\title{
Josiah Wedgwood and his Influence on the English Pottery Industry.
}

\author{
By S. R. Hind,
}

$\mathrm{I}^{\mathrm{N}}$ $\mathrm{N}$ order to understand the state of the pottery industry of Britain at the time Wedgwood took up his labours, it is necessary to go back to a period some forty years before his birth in 1730 . At this time the products of the Staffordshire potteries consisted of heavy, coarse ware made of local clays in the form of platters, drinking and cooking-pots, butter-pots, and similar articles. These were crudely made, usually on the potter's wheel, ornamented in an elementary way, if at all, and glazed imperfectly by means of raw lead preparations such as galena.

One great exception, indicative of the change to come, must be made on behalf of the secret manufactory of the brothers Elers, natives of Nuremberg, who had come over from Amsterdam and developed a new kind of ware at Bradwell Wood, near Burslem. They manufactured a fine red stoneware out of carefully prepared local clay, the articles being lathe turned whilst partially dry, ornamented with applied designs of sharp outline, and finally salt glazed. These new methods ultimately became diffused in the neighbourhood, with some loss in effect for the time being, but an enormous stimulus to progress, by the efforts of the elder Astbury.

Astbury's use of washes of finer clays marked the beginning of a line of development which led to various forms of ornamentation, engobes, and glazes of composite and infinitely superior character. The uses of various lead compounds, feldspar, borax, and other glaze components began to be explored and their qualities modified by a preliminary fusion or fritting.

The advantages of flint in admixture with both bodies and glazes soon came into prominence. Its preparation by dry grinding, following calcination, led to many cases of what we know now as silicosis; this danger was reduced very markedly by a painter named Benson, who introduced the wet grinding process. Later improvements in the application of water and wind power and the use of mill runners of chert, a fairly pure form of silica, in place of granite, take us down to the early careers of Brindley and Wedgwood.

Other notable advances were in connexion with plaster of Paris moulds, the use of the red clay colour-trials of Thomas and John Wedgwood in controlling the firing of ovens, an increasing appreciation and importation of ball-clay and pipe-clay from the south of England, the use of the slip-kiln, and the introduction of biscuit firing (that is, separate firing of the body before application of the glaze) by Enoch Wood; this at a time when Wedgwood had already launched out in his early partnership with Harrison and Alders.

By this time, a coarse cream earthenware, white or greyish-white and red stoneware and tortoiseshell ware, were the staple of the district. The field was set for great advances, but the master-hand was lacking, and trade was even declining, owing to the competition of Delft or Dutch enamelled pottery, which was being imported in large quan. tities in 1759 , the year in which Wedgwood commenced operations as a master potter.

So much, as the briefest of summaries, must serve as an indication of the outward circumstances in which Josiah Wedgwood commenced his great work. A few details as to his early life will serve as a slight guide to his $\boldsymbol{r}_{\text {uaction }}$ to these conditions. Born the thirteenth child of a master potter in modest circumstances in Burslem, he received such education as could be obtained in the local schools. This, however, only lasted until his tenth year, when his father died and he was put to work as a potter under his eldest brother Thomas. He appears to have had the instincts of an artist and a craftsman even at this early age, and became a proficient thrower. A violent interruption in the form of an attack of virulent smallpox laid him low after two years and this left after-effects, notably a weakness in the right knee, which ultimately led to the amputation of his leg. Re. turning to work, he soon found that he could not continue 'throwing,' and had to turn his mind to other branches of the work. The variety thus enforced, coupled with the suffering and meditation incident on his illness and its after-effects, must have assisted the godly discipline of his mother in developing a noble and imaginative character, whose great and indeed sole objective was to excel in his craft.

Wedgwood's mind having a strong experimental bent, and his brother having no desire to widen the scope of his manufactures, Josiah at the close of his apprenticeship threw in his lot with Harrison and Alders, owners of a small pottery, and later with a more progressive potter named Whieldon of Fenton Low. Even this period was not uninterrupted by illness, which only appears to have tem. pered the true steel of the young potter, and left his energies unabated. By now (1759) he had studied every branch of the manufacture of ordinary pottery and even its sale; being impatient of further restriction, he commenced business at the Ivy House, Burslem, having engaged a second cousin, Thomas Wedgwood. Thomas had previously been a potter at Worcester and afterwards became his cousin's partner in the manufacture of ' useful' ware, chiefly the improved cream ware. The business grew rapidly, potters were trained to the improved methods, and by 1763 the need for increased accommodation had become so pressing that Wedgwood took over the Brick House Works (Bell House), Burslem. His close application to every detail of manufacture, improvements resulting from constant experiment and subdivision of labour, resulted in what, in those days, was nothing less than mass production.

Having established his manufacturing unit on sound lines, Wedgwood now turned more and more of his attention to organising his connexion with 
the outside world. An illness due to a further injury to his leg on the way to Liverpool led to a long stay in that town and a friendship with Thomas Bentley, out of which developed a partnership which relieved Wedgwood of a great part of the exploitation of his wares. Bentley gradually transformed his business from that of a general merchant and exporter to that of pottery merchant solely. Wedgwood and Bentley ultimately went into partnership in ornamental wares. The latter transferred to London and supervised the sales of Wedgwood ware in the Court circle, also managing an extensive decorating works in London. He secured artistic and other services and was a constant friend and adviser to his partner on almost every phase of the joint enterprise.

At this period Wedgwood entered into arrangements with Sadler and Green of Liverpool, with respect to the printing of outlines of on-glaze decoration according to the transfer method devised by Sadler. These outlines were afterwards filled in by hand. The method was later extended to include the whole decoration. Sadler and Green also possessed enamel kilns of their own for fixing such decoration, and did a thriving trade by buying ware, particularly from the Liverpool potteries, decorating it and reselling.

By the time these developments had taken place, Wedgwood's improved cream ware had become an important article of commerce, restored the export trade of Great Britain in pottery and been accorded Royal patronage, in honour of which it was henceforth known as Queen's ware. A further expansion of accommodation was necessary, resulting in the purchase of a new site, and the erection of what was then a model factory and village at Etruria, near Hanley. The Burslem potteries were still retained.

Wedgwood had also meanwhile been actively engaged in the improvement of local conditions, notably in taking a prominent part in the development of means of road and canal transport, and he reaped the benefit in the then ideal situation of his new works.

A new era of prosperity now opened up. The cream ware attained the height of its perfection. Exports to every part of Europe and to America continued to grow. Catherine II. of Russia commissioned the manufacture of a stupendous set of table-ware amounting to 952 pieces. A large number of these had to be specially modelled, and the plates and dishes were embellished, besides the normal rim decorations, with hundreds of paintings of English castles and mansions. Great use was made of the camera lucida in securing these views. It is doubtful whether this form of ornamentation can be considered to be in keeping with Wedgwood's excellent and restrained taste in decoration, but as a work of art, largely intended for show purposes, the set was certainly a wonderful achievement. A number of pieces corresponding to those of the set were also made for other purposes, but without the frog badge which was ordered as part of the original decoration.

Wedgwood's service to English pottery went much further than such improvements in serviceable ware as have been touched upon. He saw possibilities in ceramic products, of elevating the whole tone of artistic appreciation in the country and abroad. In his jasper body, a unique composition requiring great skill in manufacture, but yielding the finest results, he saw the possibility of reproducing works of art at a cost which would render their wide dissemination a practical proposition. Ceramics was to become to the arts as the invention of printing to the sciences. Space will not permit of any but the briefest reference to the lines this development took.

Excellent books exist to show the success he achieved. Wedgwood concentrated on every available source of artistic material, books of drawings from the antique, collections of cameos and gems, and the original works of a large number of artists, amongst whom Flaxman, Hackwood, Webber, and Tassie are pre-eminent.

The black basalt body had been improved to the point of making it an admirable medium for busts and vases. The jasper body, normally translucent and white, a delicate body of which the chief constituent was cawk or barium sulphate, was controlled as to translucency, the special difficulties encountered in its firing were overcome after lengthy experiments, and blue, green, yellow, lilac, and black bodies were prepared from it by suitable additions of colouring oxides; and their agreement with one another in firing shrinkage ensured.

The moulding of cameos, first with plaster moulds, was replaced by the use of the technically more perfect, but more troublesome moulds of fired clay. ware, and ultimately the finest results in coloured backgrounds were attained by the substitution of coloured washes or engobes for the solid coloured bodies. The use of the improved lathe was called in to add fluting, chequer, and other effects. The principal uses to which the new combination of materials and technique were put, lay in bas-relief ornament on ornamental ware of all descriptions, portrait cameos, medallions, vases, plaques, and panels for fireplaces and cabinet-work. The most famous, if not notorious, application lay in white jasper ornaments on the famous cobalt blue ground. Perhaps the most beautiful to the modern eye are the few existing examples of low relief classical ornament in white on the white ground. Undoubtedly, the most remarkable and difficult examples are the copies of the Portland or Barberini Vase.

A few words, even in such an incomplete account as this, must be devoted to Wedgwood's association with the scientific men of his day. Throughout his life he maintained as close a contact as possible with the progress of chemical and physical science. He was a regular correspondent with Priestley and Darwin (Wedgwood and Darwin were both grandparents of Charles Darwin), and well known to the fraternity of the Royal Society, to which he was elected for his clay shrinkage pyrometer. This was developed out of his experiments on controlling the heat in his ovens, and it remained for long unrivalled for the purpose.

Josiah Wedgwood made notable contribution

No. 3160, VoL. 125] 
to our knowledge of glazes, colours, decorations, saggars, and in fact practically every department of pottery manufacture. It must be admitted that the times and conditions to which he was born conspired together to favour a rapid development of the pottery industry, and that other men of his day, Spode and Turner, for example, also made worthy contributions to that development. Nevertheless, it is clear that he was their acknowledged leader and a man of the greatest generosity and natural ability.

He died in January 1795 after a life dogged by ill-health, but inspired to the last with the creative enthusiasm of his craft.

\section{The Importance of Cataclasms in Evolution.*}

By Dr. G. P. BIDDer.

A

CATACLASM is the result of an exceptional drought, flood, heat, cold, volcanic disturbance, or change in constituents of atmosphere or ocean, or other change in environment which over a large area is fatal to all species or individuals saving those which are exceptionally provided, quantitatively or qualitatively, so as to survive the ordeal. This definition is in strict agreement with Southey's use of the word in 1834 (Oxford Dict.). We may consider the essential phenomenon of a cataclasm as the reduction, by some violent happening, of a populous region of earth or sea to sterile emptiness, which is repopulated by the few survivors of the disaster. $\dagger$ Destruction may come upon all living beings from a volcano, or from a volcanic wave upon land and freshwater organisms, or from a pandemic disease upon only a single group of animals.

Darwin recognised the importance of the cataclasm, but he rarely emphasised it, probably because diluvial doctrines had so long held the field. It is now generally overlooked in theoretical discussions. The possibility of a given speciescharacter or individual variation having survival value is commonly discussed from the point of view only of normal environment, without recognising that eschatological environment has equal or greater importance in the selection of races, and in regard to many characters must have been the only decisive factor.

If a small heritable quantitative or qualitative difference can lead to the survival of an individual in a catholic danger which destroys all individuals of the species not endowed with such a difference, then, though the danger recurs but once in 50,000 years, that difference must eventually be stereotyped as a character of the species. In the intervening 50,000 years of peace many successful variations may take place which do not include this saving difference, but they are pruned by the next similar cataclasm, the survivors of which will again all conform to type. Thus cataclasmic selection may enforce specific characters which are normally useless.

The position may be illustrated by considering at length the brief argument on the giraffe's neck

* Slightly modified from a paper read before the Linnean Society abstract in Proc. Linn. Soc. for Feb. 6, 1930.

† The word 'cataclysm' has a valuable use in its original technical significance of a widespread submergence of land. This was a legitimate application of the English form of the Greek word in Matthew xxiv, 38, the Vulgate Latin 'diluvium' having been reserved for the supposed post-Tertiary universal deluge. The modern protean use of "cataclysm" threatens to render the word unserviceable. in the sixth edition of the "Origin of Species", recalled to notice by Pycraft's interesting essay in Science Progress for January last. Darwin says: "The individuals which were the highest browsers and were able during dearths to reach even an inch or two above the others, will often have been preserved". The value of the passage is that it explains how, in the face of universal death, a very small quantitative advantage may save the individual. In normal times a giraffe with a neck two inches longer might gather 1 per cent more leaves than his brother and be perhaps $\frac{1}{2}$ per cent better nourished; and the advocatus diaboli is in his rights when he claims that this would have no survival value. In the great dearth, when all on the ground is eaten and the trees are stripped up to the full height that the tallest giraffes can reach, all must die of starvation. Yet if half a dozen giraffes now come who can reach two inches higher, they will find two inches of untouched leaves on every tree, and they alone may survive, to transmit their slightly longer necks to their progeny after the cataclasm. $\ddagger$

On these premises, there is little positive advantage to the progeny in having a long neck; the advantage in a dearth is in having a longer neck than the rest of the population. At the next similar cataclasm the survivors would be those with necks two inches longer than the now increased usual maximum of neck, and the survivors of the second cataclasm would transmit necks two increments longer than those of the original population. In a dearth, two inches added to the mean or modal length of neck might add, perhaps, a few hours to the duration of dearth required to kill off the herd; but the deviational excess of the length of neck in a single individual may ensure his solitary survival through another month of dearth. If this deviational excess be heritable, we have it enforced on the post-cataclasmal population as an example of what we may term 'futile' evolution; defining

* Such transmission will obviously take place to all descendants if the two-inch longer neck be a Mendelian recessive mutation, and to $8 / 9$ of the descendants if it be a Mendelian dominant, and the survivors show a typical sample of $2 D D+4 D R$. Most biologists would agree that there is no transmission if the extra height is merely 'metampic'-due to especially favourable accidents of nutrition and the like. But on Galton's " famous law of Heredity, which declared that to the total heritage of the offspring the parents on the average contribute $1 / 2$, the grandparents 1/4", etc., if we agree with Bateson (1909, "Mendel's Principles of Heredity", p. 6) that " there was admittedly a statistical accord between Galton's theory and some facts of heredity " and consider that the facts as to stature in giraffes probably come into this category,-then, if all the pre-cataclasmal ancestry be assumed normal, all the post-cataclasmal progeny would have a mean which deviates from the pre-cataclasmal mean by half the deviation of the survivors through the ordeal.

No. 3160, VoL. 125] 